\title{
Remote Control Monitoring Simtem Irigasi Sprinkler Berbasis IoT Pada Tanaman Hortikultura
}

\author{
${ }^{1}$ Fakhrul Nasrulloh, ${ }^{2}$ Galih Wasis Wicaksono, ${ }^{3}$ Zamah Sari \\ Jurusan Teknik Informatika Universitas Muhammadiyah Malang \\ e-mail: ${ }^{1}$ fakhrulnasrulloh@gmail.com, ${ }^{2}$ galih.w.w@umm.ac.id, ${ }^{3}$ zamahsari@umm.ac.id
}

\begin{abstract}
Abstrak
Dengan adanya lahan pertanian yang melimpah di Indonesia maka diperlukan suatu perencanaan jaringan irigasi yang lebih modern, berteknologi dan berinovasi. Hal tersebut dilakukan guna menunjang sistem irigasi yang baik sehingga mampu menghasilkan kualitas pertanian yang bagus. Remote control monitoring sistem irigasi sprinkler berbasis loT (Internet of Things) merupakan rancangan jaringan irigasi sprinkler yang bisa digunakan dari jarak jauh menggunakan smartphone. Dimana pada sistem irigasi tersebut mengikuti perkembangan teknologi yang sudah berkembang di Indonesia saat ini yaitu industri 4.0. Desain dan rancangan komponen mikrokontroler sistem jaringan irigasi sprinkler berbasis loT dapat terintegrasi dengan smartphone pada Blynk App dan tentunya terkoneksi dengan jaringan internet. Untuk terwujudnya suatu sistem irigasi sprinkler perlu dilakukan implementasi dan pengujian hardware maupun software guna mengetahui kinerja dari sistem irigasi. Mikrokontroler pada sistem irigasi sprinkler ini menggunnakan ESP8266 NodeMCU v3. Pemrograman pada board ESP8266 NodeMCU menggunakan bahasa pemrograman yang sama dengan Arduino yaitu bahasa $\mathrm{C} / \mathrm{C}++$ dan untuk melakukan pengembangan pemrograman juga support dengan software Arduino IDE. Komponen mikrokontroler yang dibahas dalam penelitian ini ialah kontroler motor servo, water flow sensor, dan soil moisture sensor. Penelitian ini dilakukan di Laboratorium terbuka milik Universitas Islam Malang (UNISMA) dengan lahan asli persawahan ukuran $10 \times 10$ meter dan tanpa memperhatikan faktor cuaca.
\end{abstract}

Kata kunci: Irigasi sprinkler, IoT (Internet of Things), ESP8266 NodeMCU, Blynk App

\section{Abstract}

With the abundant agricultural land in Indonesia, a more modern, technological and innovative irrigation network planning is needed. This was done to support a good irrigation system so as to produce good agricultural quality. Remote control monitoring of the loT (Internet of Things) sprinkler irrigation system is a sprinkler irrigation network design that can be used remotely using a smartphone. Where the irrigation system follows the development of technology that has developed in Indonesia today, namely industry 4.0. The design and design of the microcontroller components of the loT-based sprinkler irrigation network system can be integrated with smartphones on the Blynk App and of course connected to the internet network. For the realization of a sprinkler irrigation system it is necessary to implement and test hardware and software to determine the performance of the irrigation system. Microcontroller in this sprinkler irrigation system uses ESP8266 NodeMCU v3. Programming on the ESP8266 NodeMCU board uses the same programming language as Arduino which is the $C / C++$ language and to develop programming it also supports Arduino IDE software. The microcontroller components discussed in this study are servo motor controllers, water flow sensors, and soil moisture sensors. This research was conducted in an open laboratory owned by the Islamic University of Malang (UNISMA) with native land of $10 \times 10$ meters in size and without regard to weather factors.

Keywords: sprinkler irrigation, IoT (Internet of Things), ESP8266 NodeMCU, Blynk App

\section{Pendahuluan}

Indonesia dikenal sebagai negara agraris dengan potensi sumber daya yang sangat melimpah. Pertanian/perkebunan merupakan sumber utama dalam memenuhi kebutuhan pangan [1]. Kondisi geografis Indonesia yang sangat strategis ditambah dengan iklim tropis 
sehingga membuat Indonesia memiliki potensi alam yang sangat bagus dibanding negara lain. Sehingga harus ada pemanfaatan sumber daya alam terdekat yaitu pertanian. Pertanian di Indonesia sendiri dapat dikatakan sebagai salah satu roda penggerak perekonomian negara dan sebagai bahan utama konsumtif masyarakat Indonesia. Saat ini pertanian dijadikan prioritas utama untuk ditingkatkan produktivitasnya. Berdasarkan data yang dirilis Badan Pusat Statistik (BPS), bila dilihat dari sisi produksi, sektor pertanian merupakan sektor kedua yang paling berpengaruh terhadap pertumbuhan ekonomi, setelah industri pengolahan, dan masih di atas sektor perdagangan dan kontruksi. Untuk triwulan II-2017 ini, sektor pertanian dalam arti luas menyumbang sebanyak 13,92 persen, sementara pada triwulan-I 2017 kontribusinya 13,59 persen. Hal ini tak luput dari Road Map pemerintah untuk menjadikan Indonesia sebagai lumbung pangan dunia di tahun 2045.

Sebagai penunjang hasil pertanian yang baik diperlukan suatu perencanaan desain irigasi yang baik dan maksimal dalam pelaksanaannya. Teknologi irigasi curah dapat meningkatkan efisiensi penggunaan air irigasi dan keseragaman irigasi yang diberikan lebih dari $80 \%$ [2]. Sistem irigasi sprinkler sangat memerlukan investasi yang besar sebagai langkah awal untuk penataan jaringan sprinkler pada lahan yang akan digunakan. Irigasi pancar (sprinkler irrigation) merupakan pemberian air pada permukaan tanah dalam bentuk percikan air seperti pancaran hujan [3]. Percikan air dihasilkan dari noozle / sprinkler yang diberikan tekanan melalui pompa ataupun gravitasi sehingga dapat menghasilkan lemparan atau percikan air yang bertekanan dan bisa menjangkau tanaman dengan maksimal.

Sistem irigasi sprinkler merupakan salah satu alternatif metode pemberian air dengan efisiensi lebih tinggi dibandingkan dengan irigasi permukaan (surface irrigation). Pada metode irigasi curah, air irigasi diberikan dengan cara menyemprotkan air ke udara dan menjatuhkannya di sekitar tanaman seperti hujan. Penyemprotan dibuat dengan mengalirkan air bertekanan melalui orifice kecil atau nozzie. Tekanan biasanya didapatkan dengan pemompaan.[4]

Pada penelitian sebelumnya [5] yang berjudul Sistem Kontrol dan Monitoring Pertumbuhan Tanaman Hortikultura pada Smart Garden menjelaskan bahwa, aplikasi untuk memantau pertumbuhan tanaman hortikultura pada smart garden dimana sistem mampu mengendalikan suhu, memantau tingkat kadar air di dalam tanah, serta dapat memberikan laporan sistem, melalui suatu aplikasi antarmuka (interface) yang mudah digunakan yaitu smartphone.

Penelitian lain yaitu dilakukan [6] yang berjudul Rancang Bangun Alat Monitoring Suhu, Kelembaban Tanah dan Ph Tanah pada Lahan Pertanian Tanaman Padi Berbasis Android. Pada penelitian tersebut menjelaskan mengenai beberapa parameter yang mempengaruhi pertumbuhan pada tanaman. Parameter tersebut yaitu pengukuran kelembaban tanah dengan menggunakan sensor soil moisture, pengukuran kadar keasaman tanah dengan menggunakan sensor PH meter serta pengukuran suhu dengan menggunakan sensor DS18B20 yang akan menggunakan mikrokontroler Arduino Uno, metode ini mampu memberikan hasil dari pengukuran pada lahan pertanian secara lansung yang bisa diakses oleh petani dan dapat memberikan notifikasi apabila kondisi pada lahan pertanian tidak sesuai dengan parameter yang telah ditetapkan, serta memberi informasi tentang rekomendasi pengapuran apa bila kadar $\mathrm{PH}$ tanah di bawah standar.

Dilihat dari beberapa abad terakhir ini kemajuan teknologi makin pesat [4], bukan hal yang tidak mungkin untuk menciptakan sebuah inovasi baru berupa sistem monitoring irigasi sprinkler yang bisa di kontrol kapanpun dan dimanapun melalui jaringan internet menggunakan suatu aplikasi antar muka (interface) yang mudah digunakan yatiu smartphone android. Bisa dibilang android didambakan oleh banyak orang karena platform yang bersifat open source, serta pengoperasian yang mudah dan fleksibel. Perancangan sistem ini menggunakan konsep Internet of Things (IoT), dimana untuk sistem kontrolnya memakai ESP8266 NodeMCU v3. Tujuan yang diharapkan ialah dapat membaca sensor soil moisture dan sensor water flow meter, serta mengendalikan motor servo untuk penyiraman otomatis.

Keterbaharuan penelitian yang dilakukan dengan penelitian sebelumnya adalah pada implementasi perancangan hardware dan implementasi perancangan sistem Android yang dikembangkan. Pada penelitian ini, penulis menggunakan ESP8266 NodeMCU v3 Lolin sebagai mikrokontroler untuk memonitoring ketinggian air pada penampung air, debit air untuk penyiraman tanaman, kelembaban tanah, dan mengontrol motor servo untuk buka tutup aliran air.

REPOSITOR, Vol. 2, No. 10, Oktober 2020, Pp. 1349-1358 
Oleh karena itu pada tugas akhir "Remote Control Monitoring Sistem Irigasi Sprinkler Berbasis IoT Pada Tanaman Hortikultura" ini diharapkan dapat membantu memudahkan pekerjaan petani konvensional dalam pengolahan irigasi lahan pertanian.

\section{Metode Penelitian}

Dalam pengembangan sistem irigasi sprinkler berbasis loT ini penulis menggunakan lahan terbuka persawahan asli di Laboratorium Universitas Islam Malang (UNISMA) dengan ukuran lahan 10×10 meter tanpa mengabaikan faktor cuaca. Tanah pada lahan percobaan tersebut secara umum memiliki tekstur liat menurut klasifikasi USDA [7].

\subsection{Waktu Dan Lokasi Penelitian}

Penelitian dimulai pada bulan Juli - Agustus. Lokasi atau tempat penelitian dilakukan di Laboratorium Universitas Islam Malang (UNISMA) pada lahan persawahan tepatnya di Jl. Green Tombro, Tasikmadu, Kec. Lowokwaru, Kota Malang.

\subsection{Jenis Penelitian}

Jenis penelitian ini merupakan penelitian dengan metode implementasi yaitu desain perancangan, pembuatan alat mikrokontroler dan pengujian model sistem irigasi. Dimana semuanya dilakukan secara bertahap mulai dari penataan lahan, perancangan hardware, pemrograman, dan pengujian software. Berikut hardware atau komponen-komponen mikrokontroler yang dibutuhkan dalam perancangan sistem irigasi sprinkler berbasis loT:

- ESP8266 NodeMCU v3 (mikrokontroler)

- Sensor kelembaban tanah (YL-69)

- Sensor debit air (ukuran $1 / 2$ Inch)

- Motor servo (MG996R)

- Modul relay 5V (2-channel)

- Power supply 5V 10A

Sedangkan untuk kebutuhan software pendukung yang dibutuhkan dalam perancangan sistem irigasi sprinkler menggunakan:

- Arduino IDE

- Blynk App

\subsection{Rancangan Sistem Irigasi Sprinkler}

Irigasi adalah suatu upaya untuk pengelolaan dan penyediaan air untuk menunjang kebutuhan pertanian [8]. Perancangan sistem irigasi ini merupakan hasil studi kasus dari penelitian sebelumnya yang sudah dilakukan di Poncokusumo, Kabupaten Malang. Ada beberapa penambahan komponen dan penambahan konsep teknologi dengan menggunakan loT (Intenet of Thing). Untuk alurnya sendiri titik pertama yaitu intake dari air sungai masuk pada penampungan air (reservoir) lalu di alirkan ke sawah atau lahan petani dengan pipa. Kemudiaan oleh petani dialirkan dengan sprinkler menuju tanamannya.

Dari konsep itulah penulis mengembangkan suatu inovasi dengan membuat mini Laboratorium dengan konsep yang sama namun intake air yang kita rubah dengan sumur bor menggunakan pompa dan mengarahkan ke tandon air (reservoir), kemudian mengalirkan ke tanaman menggunakan sprinkler ke lahan. Dalam alur tersebut menggunakan 2 tandon (reservoir) dengan tujuan untuk perilaku tanaman yang berbeda dan dapat menjangkau posisi tanaman terjauh agar tersiram dengan rata serta agar menghasilkan tekanan debit dari kedua tandon tersebut yang mengarah ke sprinkler. Sehingga diharapkan sprinkler mampu menghasilkan lemparan air yang maksimal meskipun hanya mengandalkan gravitasi tanpa pompa. Dalam skema yang sederhana itu, ditambahkan mikrokontroler dengan tujuan untuk monitoring kondisi lahan dari jarak jauh dan melakukan controlling. Berikut skema rangkaian mikrokontorler dan gambaran arsitektur umum penataan alat pada lahan pertanian: 


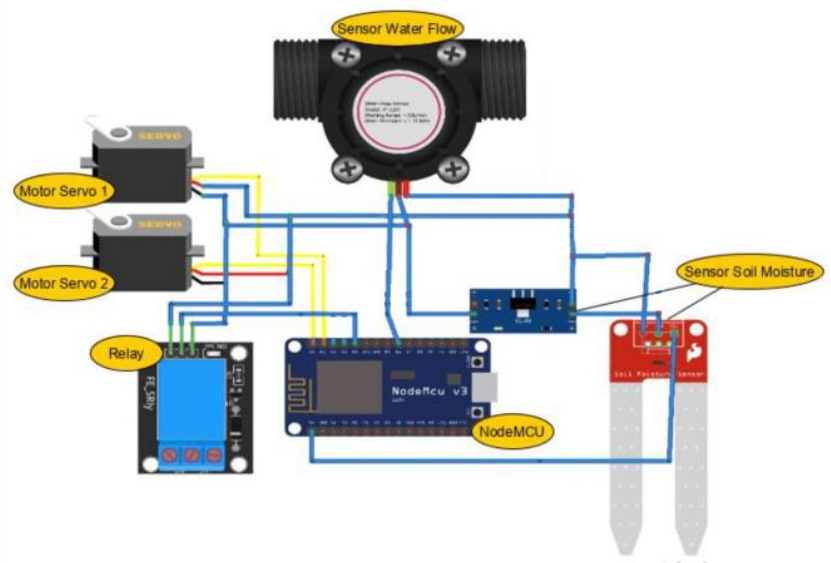

Gambar 1. Skema rangkaian mikrokontroler

Keterangan dan fungsi:

1. Sensor water flow, untuk monitoring debit air dan volume air saat penyiraman.

2. Motor servo, untuk kontroler (buka-tutup) stop kran.

3. Relay, untuk mengirim perintah (buka-tutup) motor servo.

4. Sensor soil moisture, untuk monitoring kadar air dalam tanah.

5. NodeMCU, untuk upload pemrograman dari software Arduino IDE.

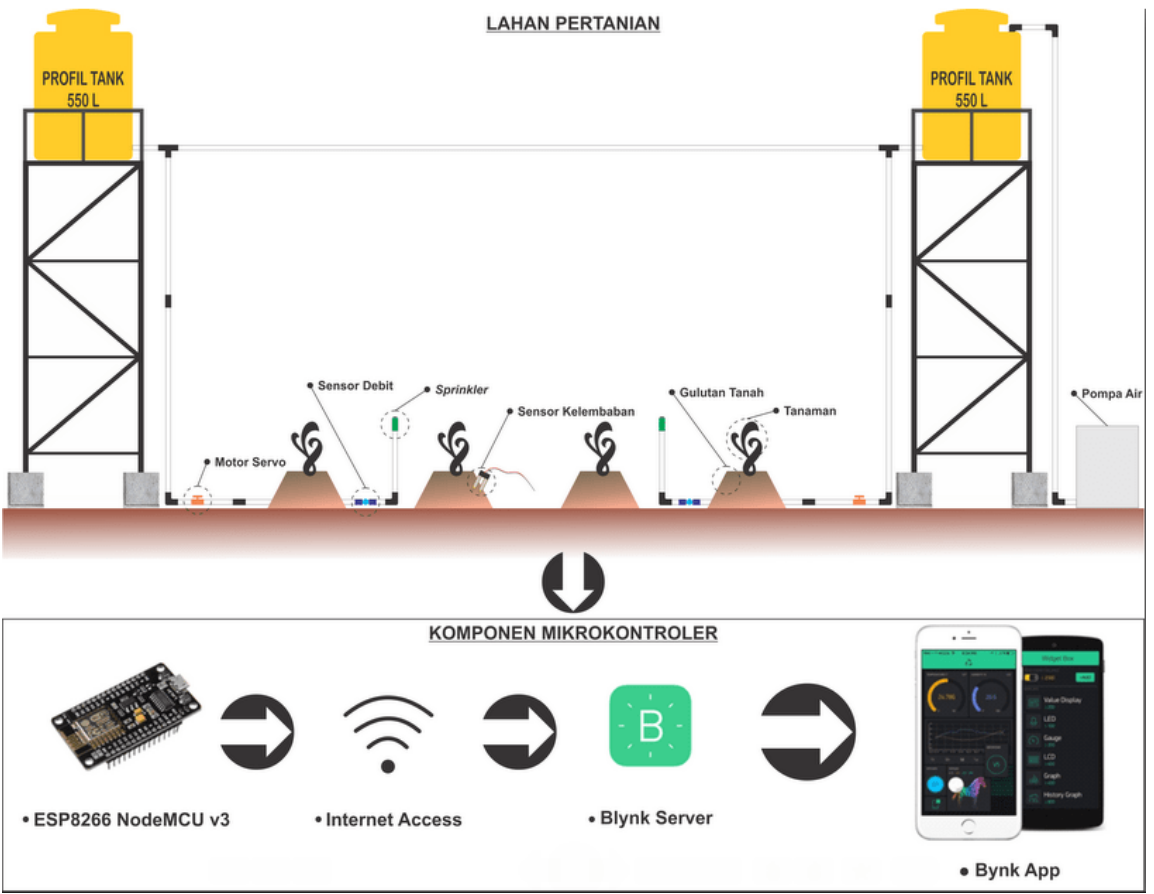

Gambar 2. Arsitektur keseluruhan sistem irigasi sprinkler

Dari Gambar 2. Arsitektur keseluruhan sistem irigasi sprinkler diatas dapat dijelaskan bahwa semua terhubung satu sama lain. Pada lahan pertanian terdapat pompa air sebagai intake pertama untuk memompa air dari sumur bor ke 2 reservoir tampungan air guna penyimpanan air sebelum digunakan untuk memenuhi kebutuhan tanaman. Pada lahan pertanian terdapat 2 reservoir, antara reservoir satu ke reservoir satunya terbuhung melalui pipa ukuran 1 inch. Dari masing-masing reservoir melalui pipa T akan dilakukan penyiraman tanaman. Sebelum sampai pada penyiraman terdapat stop kran yang dipasang motor servo guna buka-tutup aliran air dari reservoir ke penyiraman tanaman. Setelah kontroler motor servo terdapat water flow sensor yang dimaksudkan untuk memonitoring aliran air yang melewati sensor guna mengetahui debit air dan volume air saat dilakukan penyiraman tanaman. Dari water flow sensor dibagi menjadi 2 aliran

REPOSITOR, Vol. 2, No. 10, Oktober 2020, Pp. 1349-1358 
dan pada ujung pipa terdapat sprinkler guna melakukan penyiraman agar merata. Pada saat penyiraman maupun sesudah penyiraman akan termonitoring soil moisture sensor yang diletakkan pada gulutan tanah lahan pertanian.

Komponen-komponen alat dan sensor yang terpasang pada lahan pertanian dihubungkan melalui kabel yang terhubung dengan mikrokontroler ESP8266 NodeMCU v3. Dari mikrokontroler di transmisikan melalui jaringan internet untuk bisa mengakses Blynk App guna ditampilkan pada smartphone. Berikut pada Gambar 3. Diagram Alir akan dijelaskan cara kerjanya:

Gambar 3. Diagram Alir Sensor

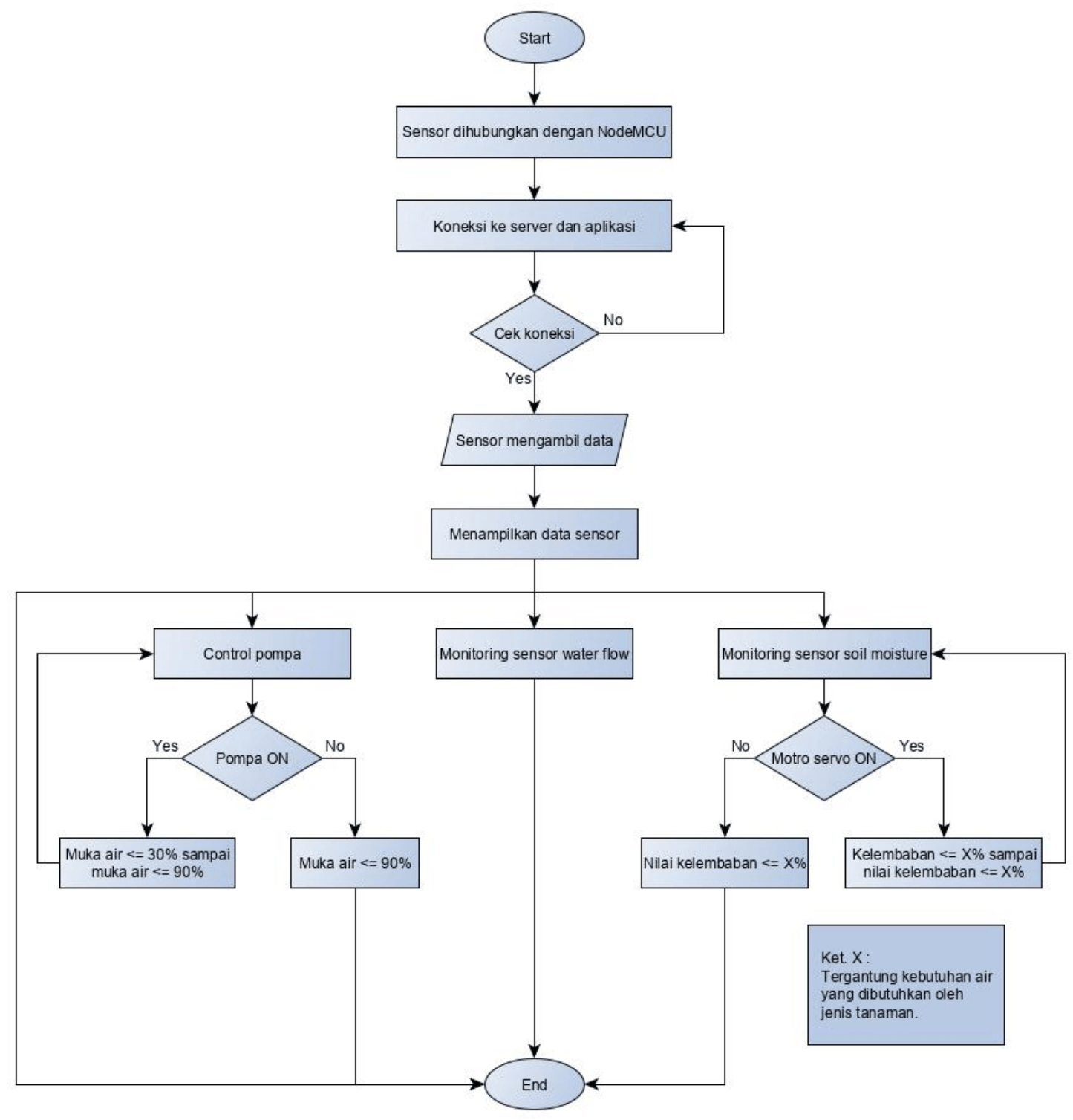

\section{Hasil Penelitian dan Pembahasan}

Sistem irigasi sprinkler ini dirancang dengan kapasitas lahan yang disesuaikan dengan kebutuhan peneliti, lahan yang digunakan merupakan lahan laboratorium yang menggunakan lahan asli persawahan. Sistem irigasi sprinkler dilengkapi dengan sensor yang diletakkan pada tiap bagian yang dianggap perlu untuk diamati.

\subsection{Implementasi Komponen Alat}



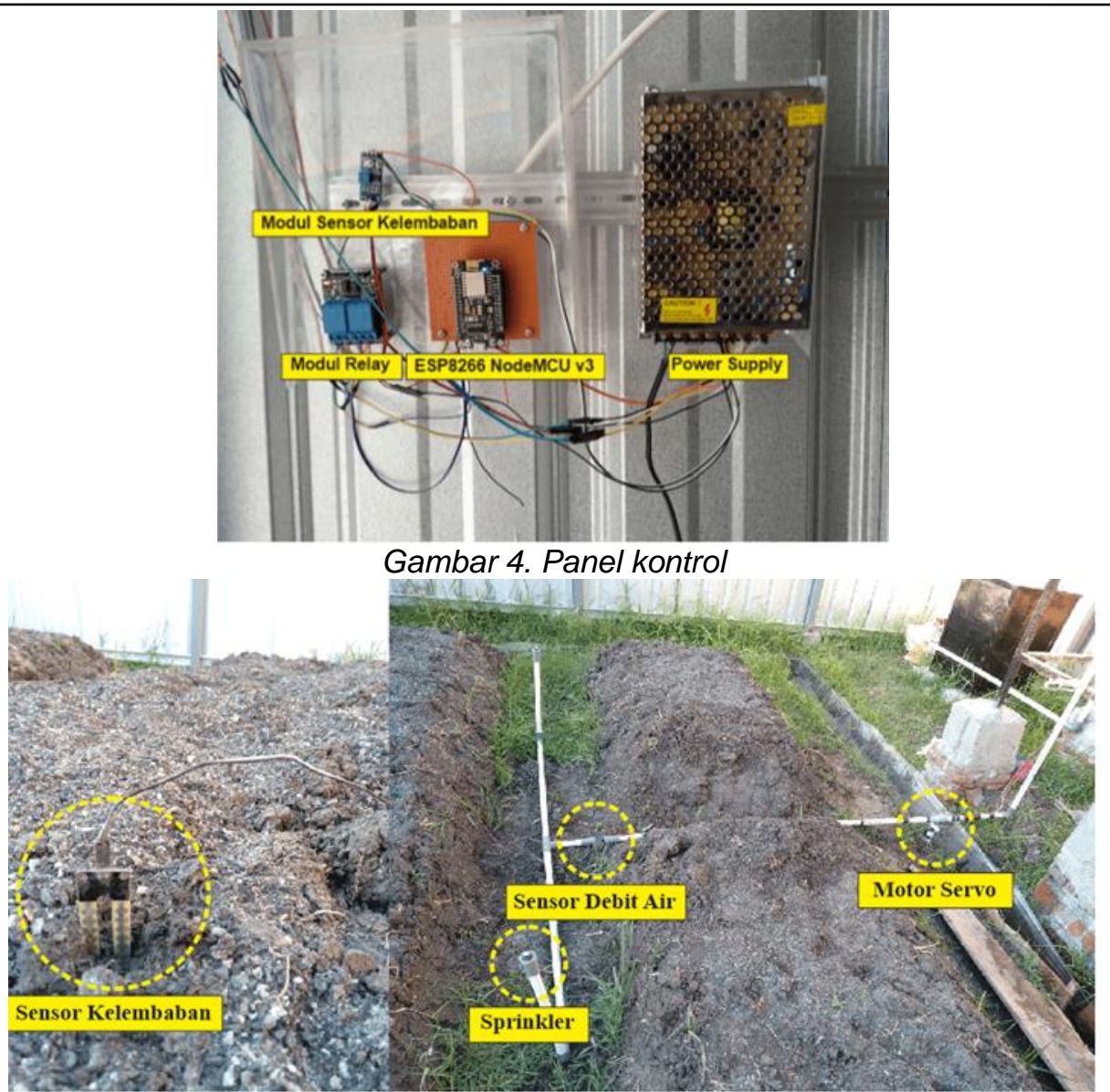

Gambar 5. Implementasi alat mikrokontroler

Perangkat sistem irigasi sprinkler berbasis Internet of Things terdiri dari 2 sensor yang terhubung pada mikrokontroler ESP8266 NodeMCU v3 diantaranya, sensor debit air (water flow sensor) yang berfungsi sebagai sensor untuk menghitung debit air yang mengalir dari recervoir ke tanaman pada sistem irigasi dan sensor kelembaban tanah (soil moisture) yang berfungsi untuk mendeteksi kadar air atau kelembaban dalam tanah.

Pada perangkat sistem irigasi juga dilengkapi dengan motor servo dan modul relay sebagai kontroling motor servo, motor servo berfungsi untuk kontrol buka-tutup sistem irigasi yang mengalir menuju tanaman, sedangkan modul relay digunakan untuk mengendalikan sirkuit tegangan tinggi dengan bantuan dari signal tegangan rendah yang berfungsi untuk kontrol on-off pompa air dari sumber air tanah ke reservoir. Tentu kontroling tidak akan berfungsi tanpa akses jaringan internet, oleh karena itu sistem irigasi bisa dioperasikan saat semua perangkat terintegrasi dengan smartphone pada Blynk App.

Adapun komponen lain yaitu power supply 5V 10A dan 4 head sprinkler jenis DN 15, power supply fungsi utamanya adalah untuk mengubah arus AC menjadi arus DC yang kemudian diubah menjadi daya atau energi yang dibutuhkan komponen-komponen pada mikrokontroler dan head sprinkler digunakan dalam penyiraman tanaman melalui sebaran yang dikeluarkan yang fungsi utamanya penghematan air sekaligus penyiraman secara merata.

Pada tahapan inilah dilakukan pengetesan fungsi dari keseluruhan sistem. Apakah dapat berfungsi sesuai dengan konsep atau tidak. Bila ada sistem yang tidak dapat bekerja dengan baik, maka harus dilakukan proses perakitan ulang setiap bagian sistemnya [9].

\subsection{Pengujian}

Penujian sistem irigasi sprinkler berbasis loT ialah dengan cara melakukan kalibrasi masing-masing alat dan sensor mikrokontroler untuk mengetahui kinerjanya. Alat dan sensor yang diuji oleh peneliti ialah motor servo, water flow sensor, dan soil moisture. 
1. Motor servo

Tabel 1. Hasil Uji Kinerja Kontroler Motor Servo

\begin{tabular}{|c|c|c|}
\hline $\begin{array}{c}\text { Hari } \\
\text { ke }-\end{array}$ & Servo I & Servo II \\
\hline 1 & Berhasil & Berhasil \\
\hline 2 & Berhasil & Gagal \\
\hline 3 & Berhasil & Gagal \\
\hline 4 & Berhasil & Berhasil \\
\hline 5 & Berhasil & Berhasil \\
\hline
\end{tabular}

Tabel 1. merupakan hasil pengujian kontroler motor servo untuk mengetahui kinerjanya. Pengujian dilakukan selama 5 hari berturut-turut sewaktu penyiraman. Dari data tersebut dapat disimpulkan bahwa kontroler motor servo mampu mengontol sistem irigasi sprinkler untuk penyiraman tanaman. Adapun percobaan "Gagal" pada Servo II dikarenakan ada kesalahan pada kabel yang digunakan terlalu jauh dengan panel kontrol dan kecil, tetapi setelah kabel diganti yang lebih besar kontrol Servo II kembali normal.

2. Water flow sensor

Tabel 2 Data Uji Kinerja Sensor Debit Air

\begin{tabular}{|c|c|c|}
\hline $\begin{array}{c}\text { Percobaan } \\
\text { ke - }\end{array}$ & $\begin{array}{c}\text { Debit } \\
\text { (liter/menit) }\end{array}$ & $\begin{array}{c}\text { Volume } \\
\left(\mathrm{cm}^{3} / \text { menit }\right)\end{array}$ \\
\hline 1 & 5,682 & 5682 \\
\hline 2 & 5,634 & 5634 \\
\hline 3 & 5,598 & 5598 \\
\hline 4 & 5,587 & 5587 \\
\hline 5 & 5,456 & 5456 \\
\hline 6 & 5,476 & 5476 \\
\hline 7 & 5,466 & 5466 \\
\hline 8 & 5,438 & 5438 \\
\hline 9 & 5,350 & 5350 \\
\hline 10 & 5,265 & 5265 \\
\hline
\end{tabular}

Tabel 2 merupakan hasil percobaan 10 kali dengan acuan pada Gambar 4.13 yaitu monitoring sistem irigasi sprinkler berbasis loT melalui smartphone. Dari data tersebut dapat disimpulkan bahwa water flow sensor mampu membaca aliran air saat penyiraman tanaman.

3. Soil moisture sensor

Sensor kelembapan tanah adalah sensor yang dapat membaca kadar air dalam tanah [10]. Perlakuan penyiraman dilakukan menggunakan 2 perlakuan yang berbeda yaitu penyiraman secara manual dan penyiraman otomatis menggunakan smartphone berbasis loT. Pengamatan dilakukan dengan cara melakukan penyiraman setiap hari menggunakan sprinkler yang dilakukan mulai dari hari setelah pindah tanam sampai panen. Pengujian kelembaban tanah dilakukan untuk mengetahui banyaknya air yang terkandung dalam tanah. Uji kelembaban dilakukan selama 10 hari berturut-turut yaitu sebelum penyiram, setelah penyiraman, dan pada saat pukul 16.00 WIB. Berikut ini adalah tabel hasil pengujian kelembaban tanah dengan perlakuan manual $\left(\mathrm{P}_{1}\right)$ dan perlakuan otomatis $\left(\mathrm{P}_{2}\right)$ :

Tabel 3. Kelembaban Tanah Pada Perlakuan $\mathrm{P}_{1}$

\begin{tabular}{|c|c|c|c|c|}
\hline \multirow{3}{*}{ Perlakuan } & \multirow{3}{*}{$\begin{array}{c}\text { Hari } \\
\text { Ke- }\end{array}$} & $\begin{array}{c}\text { Sebelum } \\
\text { Penyiraman }\end{array}$ & $\begin{array}{c}\text { Setelah } \\
\text { Penyiraman }\end{array}$ & $\begin{array}{c}\text { Pukul } \\
16.00 \text { WIB }\end{array}$ \\
\hline \multirow{3}{*}{} & 1 & 65,3 & 39,6 & 64,2 \\
\cline { 2 - 5 } & 2 & 63,9 & 35,5 & 63,3 \\
\hline
\end{tabular}




\begin{tabular}{|c|c|c|c|c|}
\hline \multirow{5}{*}{} & 3 & 63,6 & 36,6 & 64,4 \\
\cline { 2 - 5 } & 4 & 63,3 & 35,2 & 63,3 \\
\cline { 2 - 5 } & 5 & 60,4 & 34,1 & 63,9 \\
\cline { 2 - 5 } $\mathrm{P}_{1}$ & 6 & 62,6 & 33,2 & 66,6 \\
\cline { 2 - 5 } & 7 & 62,9 & 32,2 & 64,2 \\
\cline { 2 - 5 } & 8 & 63,6 & 30,6 & 65,4 \\
\cline { 2 - 5 } & 9 & 62,5 & 31,2 & 64,8 \\
\hline & 10 & 63,3 & 29,7 & 62,2 \\
\hline
\end{tabular}

Tabel 4. Kelembaban Tanah Pada Perlakuan $\mathrm{P}_{2}$

\begin{tabular}{|c|c|c|c|c|}
\hline \multirow[b]{2}{*}{ Perlakuan } & \multirow[b]{2}{*}{$\begin{array}{l}\text { Hari } \\
\mathrm{Ke}-\end{array}$} & \multicolumn{3}{|c|}{ Kelembaban (\%) } \\
\hline & & $\begin{array}{c}\text { Batas } \\
\text { Minimal }\end{array}$ & $\begin{array}{c}\text { Batas } \\
\text { Maksimal }\end{array}$ & $\begin{array}{c}\text { Pukul } \\
16.00 \text { WIB }\end{array}$ \\
\hline \multirow{10}{*}{$\mathrm{P}_{2}$} & 1 & \multirow{10}{*}{62} & \multirow{10}{*}{32} & 63,6 \\
\hline & 2 & & & 61,8 \\
\hline & 3 & & & 64,2 \\
\hline & 4 & & & 61,9 \\
\hline & 5 & & & 62,4 \\
\hline & 6 & & & 64,9 \\
\hline & 7 & & & 65,3 \\
\hline & 8 & & & 63,1 \\
\hline & 9 & & & 62,7 \\
\hline & 10 & & & 64,1 \\
\hline
\end{tabular}

Tabel 5. Rata-rata Kelembaban Tanah Pada Pukul 16.00 WIB

\begin{tabular}{|c|c|c|}
\hline \multirow{2}{*}{ Perlakuan } & \multicolumn{2}{|c|}{ Rata-rata Kelembaban Tanah Pada Pukul 16.00 WIB } \\
\cline { 2 - 3 } & Kelembaban (\%) & Kondisi Tanah \\
\hline $\mathrm{P}_{1}$ & 64,2 & Lembab \\
\hline $\mathrm{P}_{2}$ & 63,4 & Lembab \\
\hline
\end{tabular}

Hasil rata-rata kelembaban tanah pada pukul 16.00 WIB yang diberi perlakuan cara penyiraman yang berbeda tidak menunjukkan pengaruh yang signifikan terhadap kondisi kelembaban tanah. Hal demikian menunjukkan bahwa kinerja sensor kelembaban bekerja dengan baik.

\subsection{Monitoring Sistem Irigasi}

Skema rangkaian software keseluruhan sistem irigasi sprinkler berbasis loT pada Blynk App merupakan gambaran secara keseluruhan dari tampilan remote control monitoringi. Berikut tampilan interface pada smartphone. 


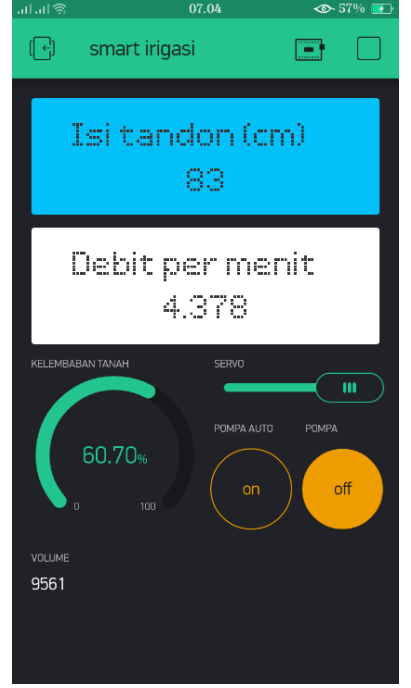

Gambar 6. Tampilan sistem irigasi sprinkler pada smartphone

Pengujian ini dilakukan untuk mengetahui apakah keseluruhan sistem telah bekerja dengan baik sehingga dapat dikontrol dan dimonitoring melalui smartphone.

Diasumsikan batas tertinggi isi tandon adalah $90 \mathrm{~cm}$ dan batas terendah $30 \mathrm{~cm}$, artinya saat isi tandon pada posisi $30 \mathrm{~cm}$ maka pompa otomatis mengisi tandon dan otomatis berhenti di posisi air isi tandon $90 \mathrm{~cm}$. Untuk $L C D$ debit per menit dan nilai volume merupakan hasil baca dari water fllow sensor. Fitur slider merupakan kontroler dari motor servo dan fitur gauge merupakan monitoring dari pembacaan soil moisture sensor. Untuk button pompa auto dan pompa merupakan ontroler dan monitoring dari pompa air untuk pengisian air ke reservoir.

\section{Kesimpulan}

Dari uraian hasil dan analisis yang telah dilakukan, diambil beberapa kesimpulan sesuai dengan rumusan masalah sebagai berikut:

1. Desain dan rancangan remote control monitoring sistem irigasi sprinkler berbasi loT berhasil terintegrasi smartphone dengan baik:

- Hasil implementasi komponen motor servo sudah terpasang di lapangan dan mampu melakukan perintah (buka-tutup) stop kran.

- Hasil implementasi water flow sensor sudah terpasang di lapangan dan mampu membaca aliran air pada pipa sistem irigasi sprinkler pada saat penyiraman tanaman.

- Hasil implementasi soil moisture sensor sudah terpasang di lapangan dan mampu membaca kadar air dalam tanah.

- Hasil implementasi keseluruhan komponen mikrokontroler sudah saling terintegrasi dengan baik.

2. Kontrol dan monitoring sistem irigasi sprinkler pada tanaman sawi pokcoy berhasil di kendalikan dan di pantau jarak jauh melalui smartphone.

- Kalibrasi dan pengujian motor servo berhasil mampu di kontrol melalui smartphone.

- Kalibrasi dan pengujian water flow sensor berhasil memonitoring debit air dan volume air melalui smartphone.

- Kalibrasi dan pengujian soil moisture sensor berhasil melakukan pengamatan.

- Kalibrasi keseluruhan skema rangkaian (software) berhasil memfungsikan fitur kontroling dan monitoring sesuai fungsinya dan mudah digunakan.

\section{Saran}

Dari hasil pengamatan pada penelitian ini maka ada beberapa saran yang disampaikan perihal analisa Remote Control Monitoring Sistem Irigasi Sprinkler Berbasis IoT Pada Tanaman Hortikultura.

1. Penelitian ini masih berskala laboratorium dengan lahan yang tidak terlalu besar sehingga tidak memperhitungkan faktor cuaca dan iklim. Untuk selanjutnya bisa diterapkan dengan lahan persawahan yang lebih luas. 
2. Penelitian ini sudah menggunakan mikrokontroler dan sudah terkoneksi pada smartphone melalui IoT. Namun perlu penyempurnaan lagi, sehingga penelitian selanjutnya bisa disempurnakan lagi.

3. Penelitian ini menggunakan 1 jenis tanaman hortikultura yaitu sawi pakcoy, jadi untuk penelitian selanjutnya bisa ditambahkan beberapa jenis tanaman.

\section{Refrensi}

[1] M. D. Syamsiar, M. Rivai, and S. Suwito, "Rancang Bangun Sistem Irigasi Tanaman Otomatis Menggunakan Wireless Sensor Network," J. Tek. ITS, vol. 5, no. 2, 2016.

[2] S. Iqrima Hana, N. S. Juliyanti, I. Muhamad, and S. Imbarwati, "Metode Irigasi Curah dan Irigasi Tetes Pendahuluan," Digilib.Uinsgd, no. 2011, 2017.

[3] dona dwi Luckytasari, jadfan sidqi Fidari, and E. Purwati, "Perencanaan Jaringan Irigasi Pancar (Sprinkler Irrigation) Pada Tanaman Cabai (Capsicum annum L.) Di Desa Sumberkima Kecamatan Gerokgak Kabupaten Buleleng Provinsi Bali," 2018.

[4] D. Rahmawati and K. Aji, "PERANCANGAN KEBUN MINI HEMAT AIR DENGAN SISTEM MIKROIRIGASI FUZZY OTOMATIS MENGGUNAKAN ARDUINO," J. IIm. rekayasa, vol. 8, no. 2, pp. 95-108, 2015.

[5] D. megah Sari, Z. B. Hasanuddi, and Dewiani, "Sistem Kontrol Dan Monitoring Pertumbuhan Tanaman Hortikultura Pada Smart Garden," J. IT, vol. 8, no. 1, pp. 6-15, 2017.

[6] R. Efendi, "RANCANG BANGUN ALAT MONITORING SUHU, KELEMBAPAN TANAH DAN PH TANAH PADA LAHAN PERTANIAN TANAMAN PADI BERBASIS ANDROID," pp. 1-120, 2019.

[7] S. K. Saptomo, R. Isnain, and B. I. Setiawan, "IRIGASI CURAH OTOMATIS BERBASIS SISTEM PENGENDALI MIKRO," vol. 8, no. 2, pp. 115-125, 2013.

[8] D. Setiadi and M. N. A. Muhaemin, "PENERAPAN INTERNET OF THINGS (IoT) PADA SISTEM MONITORING IRIGASI (SMART IRIGASI)," J. Infotronik, vol. 3, no. 2, pp. 95102, 2018.

[9] T. A. Zuraiyah, M. I. Suriansyah, and A. P. Akbar, "Smart Urban Farming Berbasis Internet Of Things ( IoT )," Inf. Manag. Educ. Prof., vol. 3, no. 2, pp. 139-150, 2019.

[10] R. Setiobudio and C. E. Suharyanto, "Sistem Irigasi Otomatis pada Tanaman Padi Menggunakan Arduino dan Sensor Kelembapan Tanah," J. ICT Inf. Commun. Technol., vol. 18, no. 1, pp. 1-10, 2019. 